\title{
Phytotoxicity of Brominated Diphenyl Ether-47 (BDE-47) and Its Hydroxylated and Methoxylated Analogues (6-OH-BDE-47 and 6-MeO-BDE-47) to Maize (Zea mays L.)
}

\author{
Xuehui $\mathrm{Xu}{ }^{\dagger}$ Honglin Huang, ${ }^{\dagger}$ Bei Wen, ${ }^{\dagger}$ Sen Wang, ${ }^{\dagger, \dagger}$ and Shuzhen Zhang ${ }^{*}{ }^{\dagger}$ \\ ${ }^{\dagger}$ State Key Laboratory of Environmental Chemistry and Ecotoxicology, Research Center for Eco-Environmental Sciences, Chinese \\ Academy of Sciences, P.O. Box 2871, Beijing 100085, China \\ ${ }^{\ddagger}$ Department of Environmental Sciences, College of Urban and Environmental Sciences, Northwest University, Xi'an 710027, China
}

Supporting Information

ABSTRACT: Polybrominated diphenyl ethers (PBDEs), methoxylated PBDEs (MeO-PBDEs), and hydroxylated PBDEs (OHPBDEs) are widely found in various environmental media, which is of concern given their biological toxicity. In this study, the phytotoxicities of BDE-47, 6-MeO-BDE-47, and 6-OH-BDE-47 to maize (Zea mays L.) were investigated by an in vivo exposure experiment. Results showed that BDE-47, 6-MeO-BDE-47, and 6OH-BDE-47 inhibited seed germination and seedling development, and elevated malondialdehyde (MDA), carbonyl groups, and phosphorylated histone $\mathrm{H} 2 \mathrm{AX}$ levels in maize roots, suggesting the inducement of lipid peroxidation, protein carbonylation, and DNA damage to maize. Exposure to BDE-47, 6-MeO-BDE-47, and 6-OH-BDE-47 caused the overproduction of $\mathrm{H}_{2} \mathrm{O}_{2}, \mathrm{O}_{2}{ }^{\bullet-}$, and $\bullet \mathrm{OH}$, and elevated the activities of antioxidant enzymes in the roots. In addition, 6-OH-BDE-47 caused more severe damage and reactive oxygen species (ROS) generation in maize than did BDE-47 and 6-MeO-BDE-47. These results demonstrated the phytotoxicities of BDE-47, 6-OH-BDE-47, and 6-MeO-BDE-47 to maize, and clarified that overproduction of ROS was the key mechanism leading to toxicity. This study offers useful information for a more comprehensive understanding of the environmental behaviors and toxicities of PBDEs, MeO-PBDEs, and OH-PBDEs.

\section{INTRODUCTION}

As brominated flame retardants, polybrominated diphenyl ethers (PBDEs) have been widely used in various household and industrial products since the 1970s, including electronic equipment, plastics, textiles, and building materials. ${ }^{1}$ Over the past three decades, PBDE concentrations in various biota and environmental media have doubled every four to six years and their congeners have been classified as highly toxic and recalcitrant environmental contaminants. ${ }^{2}$

Hydroxylated PBDEs (OH-PBDEs) and methoxylated PBDEs (MeO-PBDEs) have also been detected in biological samples, such as marine organics, plants, and human blood, ${ }^{3-5}$ and abiotic matrices, including air, surface and groundwater, sediment, and soil. ${ }^{6-8}$ Although there is no known anthropogenic source, biological and/or photochemical transformation of PBDEs can produce OH-PBDEs and MeO-PBDEs. ${ }^{9,10}$ It has been stated that OH-PBDEs in the abiotic environment can be produced through the reaction of PBDEs with atmospheric hydroxyl radicals $(\bullet \mathrm{OH}){ }^{6}$ In addition, microbes and plants play key roles in the transformation of PBDEs to OH-PBDEs and MeO-PBDEs. ${ }^{11,12}$ Recently, accumulations of $\mathrm{OH}-\mathrm{PBDEs}$ and MeO-PBDEs in soils and plants have been reported; ${ }^{8,13}$ however, their origin and behavior in the terrestrial environment are so far unclear.

Besides their wide detection in the environment, the potential toxicities of PBDEs, OH-PBDEs, and MeO-PBDEs have raised considerable concern. Results obtained by in vivo animal exposure experiments showed that some PBDE congeners can affect neurodevelopment, ${ }^{14}$ disrupt thyroid functioning, and cause thyroid tumors, ${ }^{15}$ and act as androgen and/or progestin receptor antagonists. ${ }^{16,17}$ Given the structural similarities between PBDEs and their analogues (OH-PBDEs and $\mathrm{MeO}-\mathrm{PBDEs}$ ), it is interesting to compare their differences in toxicity. Studies have shown that OH-PBDEs are more potent than parent PBDEs and corresponding MeO-PBDEs. ${ }^{18}$ For example, 6-OH-BDE-47 has more serious cytotoxicity to fish than both BDE-47 and 6-MeO-BDE-47. ${ }^{19}$ Furthermore, it has been reported that $6-\mathrm{OH}-\mathrm{BDE}-47$ has a greater affinity than either $\mathrm{BDE}-47$ or $6-\mathrm{MeO}-\mathrm{BDE}-47$ for transport protein transthyretin, inducing a decrease in plasma thyroid hormone thyroxine levels. ${ }^{17,20}$ Results obtained from in vitro exper-

Special Issue: Chemical Toxicology in China

Received: November 25, 2014

Published: January 22, 2015 
imentation and molecular dynamics simulation demonstrated that OH-PBDEs displayed greater estrogenicities than their corresponding PBDEs and MeO-PBDEs analogues, which was especially true for 6-OH-BDE-47. ${ }^{21}$ Although research on the toxic effects of PBDEs, OH-PBDEs, and MeO-PBDEs has shown great progress, most studies have focused on their neurotoxicity, endocrine disruption, and genotoxicity on aquatic species and mammals. ${ }^{15,22,23}$ To our knowledge, no study has been conducted in regard to their phytotoxicity on terrestrial plants.

The objective of this study was to investigate the toxic effects of BDE-47, 6-MeO-BDE-47, and 6-OH-BDE-47 on maize (Zea mays L.). The effects of different concentrations of BDE-47, 6$\mathrm{MeO}-\mathrm{BDE}-47$, and 6-OH-BDE-47 on seed germination and root and shoot elongation were investigated. The contents of malondialdehyde (MDA), free carbonyl groups, and phosphorylated histone $\mathrm{H} 2 \mathrm{AX}(\gamma-\mathrm{H} 2 \mathrm{AX}$ foci) were investigated to determine the oxidative damage of BDE-47, 6-MeO-BDE-47, and 6-OH-BDE-47 to plasmalemma, protein, and DNA of maize. To achieve a better understanding of the toxic mechanisms involved, the activities of antioxidant enzymes, including superoxide dismutase (SOD), peroxidases (POD), and catalase (CAT), were measured, and ROS generation in maize was detected. The results will provide useful information for better understanding the behavior and phytotoxicity of PBDEs in the terrestrial environment.

\section{MATERIALS AND METHODS}

Chemicals and Reagents. Standards of BDE-47, 6-OH-BDE-47, and 6-MeO-BDE-47 were purchased from AccuStandard (AccuStandard, New Haven, CT, USA). Dihydroethidium (DHE), $\alpha$-phenyl- $N$ tert-butylnitrone (PBN), 2', $7^{\prime}$-dichlorofluorescein diacetate (DCF$\mathrm{DA})$, and 2,4-dinitrophenylhydrazine (DNPH) were obtained from Sigma-Aldrich Company (purity $>99.9 \%$, Sigma Inc., St. Louis, MO, USA). Distilled water was used in all experiments. Solvents of acetone and dimethyl sulfoxide (DMSO) were of HPLC grade (Thermo fisher, MA., USA). Other chemicals used were of analytical grade.

Seed Germination Test. The impact of BDE-47, 6-OH-BDE-47, and 6-MeO-BDE-47 on maize (Zea mays L.) seed germination was tested. Maize seeds were obtained from the Chinese Academy of Agricultural Sciences, Beijing, China. Prior to the germination test, seeds of similar size were selected and surface-sterilized in $3 \%(\mathrm{v} / \mathrm{v})$ $\mathrm{H}_{2} \mathrm{O}_{2}$ for $30 \mathrm{~min}$, followed by thorough washing with distilled water. Fifty sterilized maize seeds were sown on Petri dishes with double layers of filter paper moistened with $25 \mathrm{~mL}$ of test solution. The test solutions were prepared by dissolving standards of BDE-47, 6-OHBDE-47, and 6-MeO-BDE-47 in acetone and then diluting with distilled water. The concentrations of the test solutions were set at 0 , 5.0, 10.0, and $15.0 \mu \mathrm{g} \mathrm{L}^{-1}$ for each compound. The acetone content in the test solutions was less than $0.1 \%(\mathrm{v} / \mathrm{v})$. The $\mathrm{pH}$ of the test solutions was adjusted to 5.8. Blanks and controls were obtained by moistening the filter papers with $25 \mathrm{~mL}$ of distilled water and distilled water containing $0.1 \%(\mathrm{v} / \mathrm{v})$ acetone, respectively. The Petri dishes were covered with lids, and incubated at $27 \pm 0.5{ }^{\circ} \mathrm{C}$ in the dark. The test solutions were renewed every day. After $4 \mathrm{~d}$, the number of germinated seeds was counted. Seeds were considered germinated when both the radicle and coleoptile lengths were over half the seed size. The primary root length and coleoptile length of seedlings were also measured.

Hydroponic Exposure Experiment. The impact of BDE-47, 6$\mathrm{OH}-\mathrm{BDE}-47$, and 6-MeO-BDE-47 on maize seedling growth was tested. After germination for $4 \mathrm{~d}$, five uniformly germinated seedlings were transferred to colored vitreous pots containing $150 \mathrm{~mL}$ of each test solution (as per the test solutions above). Controls exposed to Hoagland nutrient solution and blanks exposed to Hoagland nutrient solution containing $0.1 \%(\mathrm{v} / \mathrm{v})$ acetone were included. Pots were kept in a controlled environment growth chamber at a light intensity of 250 $\mu$ mol $\mathrm{m}^{-2} \mathrm{~s}^{-1}$ provided by supplementary illumination with a photoperiod of $14 \mathrm{~h}$ each day, at a $25 / 20^{\circ} \mathrm{C}$ day/night temperature regime, and relative humidity of $80 \%$. The test solutions were renewed every day. All treatments were set up in triplicate. After $3 \mathrm{~d}$ of exposure, maize seedlings were harvested and rinsed. The shoot and root lengths were measured. Electro paramagnetic resonance (EPR) and confocal laser-scanning microscope (CLSM) determinations were performed for roots immediately after harvest. The remaining plant tissues were frozen in liquid nitrogen and stored at $-80{ }^{\circ} \mathrm{C}$ for $\mathrm{MDA}$ content and antioxidative enzyme activity analysis.

Oxidative Damage Assay. MDA content was measured using the thiobarbituric acid (TBA) test described by Aravind and Prasad. ${ }^{24}$ The quantification of carbonyl groups was selected as a parameter for oxidative damage to proteins. The carbonylation assay was based on the reaction of carbonyl groups with DNPH and was measured according to Levine. ${ }^{25}$ Histones were isolated as described previously, and the level of $\mathrm{H} 2 \mathrm{AX}$ phosphorylation in the histone samples was analyzed with a plant $\gamma$-H2AX enzyme-linked immunosorbent assay (ELISA) kit (RB, USA). ${ }^{26}$ Procedures are detailed in the Supporting Information.

Antioxidation Enzyme Response Assay. Fresh roots (1.0 g) were ground in a mortar with $8 \mathrm{~mL}$ of PBS buffer, $0.05 \mathrm{M} \mathrm{NaH}_{2} \mathrm{PO}_{4}$. $\mathrm{Na}_{2} \mathrm{HPO}_{4}$ in $1 \%(\mathrm{w} / \mathrm{v})$ polyvinylpyrrolidone at $\mathrm{pH} 7.8$, in an ice bath. After centrifugation at $10,000 \mathrm{rpm}$ at $4{ }^{\circ} \mathrm{C}$ for $15 \mathrm{~min}$, the supernatant was collected for further analysis. The protein level was measured by the Bradford method ${ }^{27}$ using bovine serum albumin as the standard. The activities of SOD, CAT, and POD were determined by a UVvisible spectrophotometer (Hitachi Co., Tokyo, Japan) based on previous literature. $^{28-30}$ Detailed procedures are provided in the Supporting Information.

ROS Detection with CLSM and EPR. In situ observation was conducted with a confocal laser-scanning microscope (Leica TCS SP5, Leica Inc., Germany) to determine the real-time production of the superoxide anion $\left(\mathrm{O}_{2}^{--}\right)$and hydrogen peroxide $\left(\mathrm{H}_{2} \mathrm{O}_{2}\right)$ in maize roots according to Tanou. ${ }^{31}$ Briefly, fresh maize roots were crosscut into 2-3 mm long sections, incubated with $20 \mathrm{M} \mathrm{DHE}$ and $10 \mathrm{M}$ DCF-DA for $1 \mathrm{~h}$, respectively, and then washed with fresh Tris-HCl buffer $(10 \mathrm{mM}, \mathrm{pH} 7.4)$ for $30 \mathrm{~min}$. The detection conditions were as follows: dye excitation, $488 \mathrm{~nm}$; emitted light, $510-560 \mathrm{~nm}$; and fluorescence recorded in green and red colors for $\mathrm{H}_{2} \mathrm{O}_{2}$ and $\mathrm{O}_{2}{ }^{\bullet-}$, respectively. Fluorescence intensities of DCF-DA and DHE were analyzed using LAS AF Lite software (Leica Inc., Germany). By attributing a value of 1 to the relative fluorescence of the control sample, fluorescence intensity was expressed as an arbitrary unit for the samples.

The hydroxyl radical $(\bullet \mathrm{OH})$ was trapped with PBN in DMSO, and the PBN radical adduct in the roots was analyzed with EPR. ${ }^{32}$ In brief, $1.0 \mathrm{~g}$ of fresh roots was weighed and homogenized in a mortar with 1.0 $\mathrm{mL}$ of a freshly prepared solution of $100 \mathrm{mM}$ PBN in DMSO. The homogenate was incubated at $37{ }^{\circ} \mathrm{C}$ for $20 \mathrm{~min}$ and centrifuged at $4,500 \mathrm{rpm}$ at $4{ }^{\circ} \mathrm{C}$ for $3 \mathrm{~min}$, with the supernatant then collected. A 30 $\mu \mathrm{L}$ portion of the supernatant was transferred to a capillary tube with a diameter of $1.0 \mathrm{~mm}$ for EPR analysis. The ESR spectra were recorded with a Bruker ESP 300 spectrometer (Bruker, Germany) at room temperature. The operation conditions were as follows: microwave power, $20 \mathrm{~mW}$; microwave frequency, $9.7 \mathrm{GHz}$; center field, $347 \mathrm{mT}$; scan range, $10 \mathrm{mT}$; modulation frequency, $100 \mathrm{kHz}$; modulation amplitude, $0.25 \mathrm{mT}$; and receiver gain, $2 \times 10^{4}$ scans. The free radical intensities were calculated based on the central peak heights of the ESR signals.

Data Analysis. All data were subjected to statistical analysis using Microsoft Excel, Origin 8.0, and the SPSS, version 11.5, software. Means and standard deviation were calculated for triplicates. One-way analysis of variance (ANOVA) with Duncan's multiple-comparison test was used to assess differences among samples at $p<0.05$.

\section{RESULTS AND DISCUSSION}

Inhibition of Seed Germination and Seedling Development. There were no significant differences in seed 
Table 1. Relative Inhibition Rates of Germination and Root and Shoot Elongation of Maize Exposed to BDE-47, 6-OHBDE-47, and 6-MeO-BDE-47 for 3 Days

\begin{tabular}{|c|c|c|c|c|}
\hline \multirow[b]{2}{*}{ compds } & \multirow[b]{2}{*}{$\begin{array}{c}\text { concn } \\
\left(\mu \mathrm{g} \mathrm{L}^{-1}\right)\end{array}$} & \multicolumn{3}{|c|}{ relative inhibition rate $(\%)^{a}$} \\
\hline & & germination $^{b}$ & $\begin{array}{l}\text { coleoptile } \\
\text { length }^{b}\end{array}$ & $\begin{array}{c}\text { primary root } \\
\text { length }^{b}\end{array}$ \\
\hline \multirow[t]{3}{*}{ BDE-47 } & 5.0 & $17.6 \pm 2.1 \mathrm{a}$ & $10.1 \pm 2.2 \mathrm{a}$ & $20.8 \pm 2.7 \mathrm{a}$ \\
\hline & 10.0 & $20.3 \pm 4.1 \mathrm{a}$ & $17.7 \pm 3.1 \mathrm{a}$ & $20.4 \pm 3.1 \mathrm{a}$ \\
\hline & 15.0 & $33.8 \pm 3.7 b$ & $26.1 \pm 1.5 b$ & $37.5 \pm 1.4 b$ \\
\hline \multirow{3}{*}{$\begin{array}{l}\text { 6-MeO- } \\
\text { BDE-47 }\end{array}$} & 5.0 & $20.4 \pm 1.3 a$ & $12.3 \pm 1.4 \mathrm{a}$ & $22.3 \pm 2.3 \mathrm{a}$ \\
\hline & 10.0 & $24.4 \pm 2.6 \mathrm{ab}$ & $18.2 \pm 3.2 \mathrm{a}$ & $23.8 \pm 1.2 \mathrm{a}$ \\
\hline & 15.0 & $37.6 \pm 2.9 \mathrm{bc}$ & $29.4 \pm 4.5 b$ & $39.8 \pm 1.0 \mathrm{~b}$ \\
\hline \multirow{3}{*}{$\begin{array}{l}\text { 6-OH- } \\
\text { BDE-47 }\end{array}$} & 5.0 & $28.3 \pm 3.4 \mathrm{~b}$ & $16.9 \pm 1.4 \mathrm{a}$ & $25.7 \pm 1.6 \mathrm{a}$ \\
\hline & 10.0 & $30.8 \pm 4.2 b$ & $23.7 \pm 3.9 \mathrm{ab}$ & $28.3 \pm 2.8 a$ \\
\hline & 15.0 & $43.6 \pm 3.0 \mathrm{c}$ & $33.4 \pm 0.8 c$ & $43.7 \pm 2.8 c$ \\
\hline
\end{tabular}

${ }^{a}$ Relative inhibition rate $(\%)=\left(V_{\text {control }}-V_{\text {treatment }}\right) / V_{\text {control }} \times 100 \%$; $V_{\text {treatment }}$ and $V_{\text {control }}$ were values of germination percentage, coleoptile or primary root lengths of treatments and control, respectively. ${ }^{b}$ Values represent the mean \pm SD of three independent experiments, and different letters represent the significant differences between treatments $(P<0.05$; Duncan's test $)$.

germination and coleoptile and primary root lengths for maize between the blank and control groups, suggesting the effect of acetone on seed germination, and seedling early development was negligible.

Results showed that BDE-47, 6-MeO-BDE-47, and 6-OHBDE-47 had negative impacts on the seed germination of maize (Table 1), with 6-OH-BDE-47 having the greatest effect among the compounds. The germination percentages were $76.2 \%$, $73.6 \%$, and $66.3 \%$ for the $5 \mu \mathrm{g} \mathrm{L}^{-1}$ BDE-47, 6-MeO-BDE-47, and 6-OH-BDE-47 treatments, respectively, which were significantly lower than that of the control $(92.5 \%, P<0.05)$. The germination inhibition rate increased significantly with increasing exposure concentration, which might be attributed to the decrease in $\alpha$ - and $\beta$-amylase activities and subsequent transport of sugars to the embryo axes under contamination stress. ${ }^{33}$ It has been reported that seed coats constitute a barrier between a plant embryo and culture medium, preventing damage to the embryos from contamination until the seed coats are destroyed by the germinating embryonic roots. ${ }^{34}$ The negative impact of BDE-47, 6-MeO-BDE-47, and 6-OH-BDE47 on seed germination suggests that they could permeate through the seed coats and consequently affect the metabolism and growth of maize.

The BDE-47, 6-MeO-BDE-47, and 6-OH-BDE-47 treatments significantly inhibited the growth of maize seedlings (Table 1). The coleoptile and primary root lengths decreased in a dose-dependent manner following BDE-47, 6-MeO-BDE-47, and 6-OH-BDE-47 exposure, with 6-OH-BDE-47 showing the greatest inhibitory effect. The relative inhibition rates of root and shoot lengths for the $15 \mu \mathrm{g} \mathrm{L}{ }^{-1} 6-\mathrm{OH}-\mathrm{BDE}-47$ treatment were $43.4 \%$ and $33.4 \%$, respectively, which were significantly higher than those of the 6-MeO-BDE-47 treatment (39.8\% and $29.4 \%$ for root and shoot lengths, respectively) and the BDE-47 treatment $(37.5 \%$ and $26.1 \%$ for root and shoot lengths, respectively). In comparison, the reduction of the main root length was more pronounced than that of the coleoptile length (Table 1). Plant roots are the first point of contact for contaminants in growth media. Inhabitation in root development caused by contaminant exposure will reduce the uptake of nutrition and further affect coleoptile growth in maize.
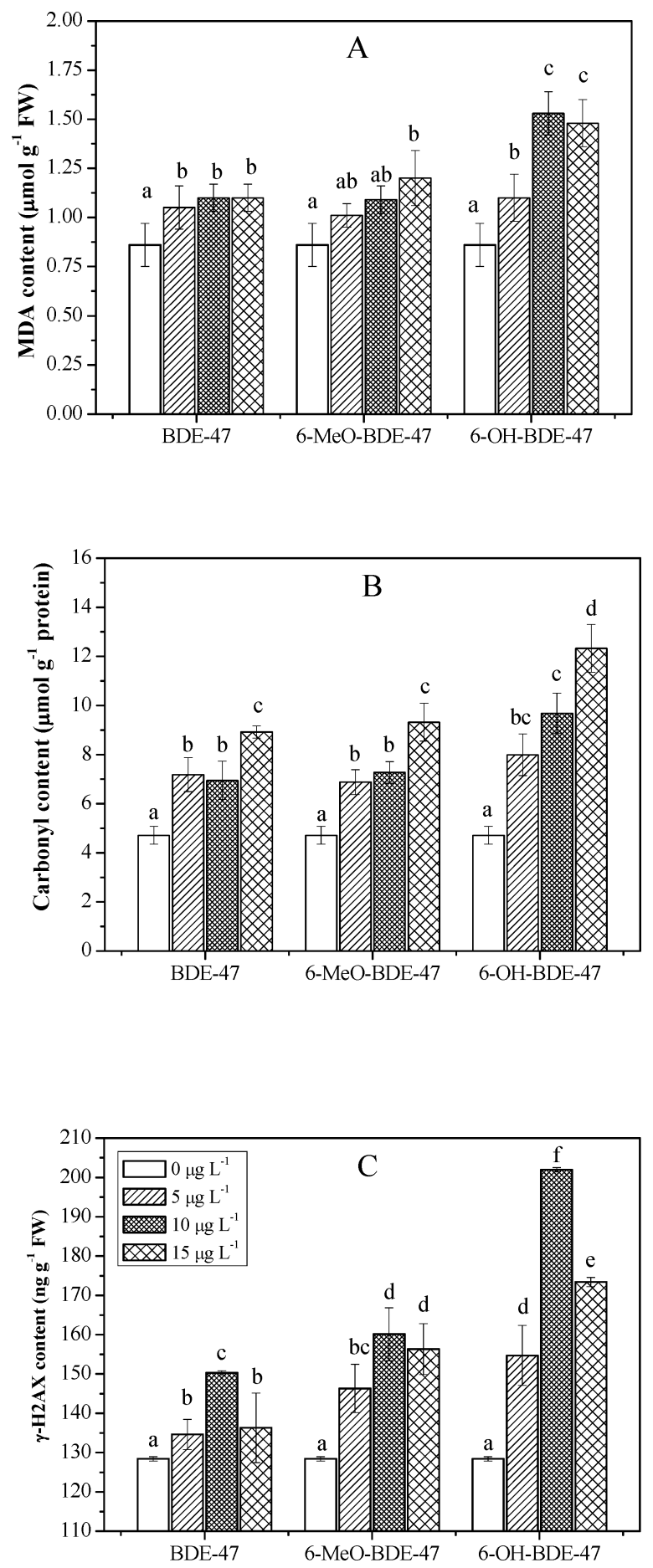

Figure 1. Physiological changes in lipid, protein, and DNA in maize roots exposed to BDE-47, 6-OH-BDE-47, and 6-MeO-BDE-47. (A) Malondialdehyde (MDA); (B) carbonyl group; (C) $\gamma$-H2AX content. Different letters represent significant differences between different treatments $(P<0.05$, Duncan's test $)$.

Lipid, Protein, and DNA Damage in Maize Roots. Treatment with BDE-47, 6-MeO-BDE-47, and 6-OH-BDE-47 caused significant oxidative damage to principal cellular components such as lipids, proteins, and DNA in maize. The MDA content in roots was significantly elevated compared with that in the control $(P<0.05)$, with the content being much higher in the 6-OH-BDE-47 treatment than those in the BDE47 or $6-\mathrm{MeO}-\mathrm{BDE}-47$ treatments at the same concentration 
A
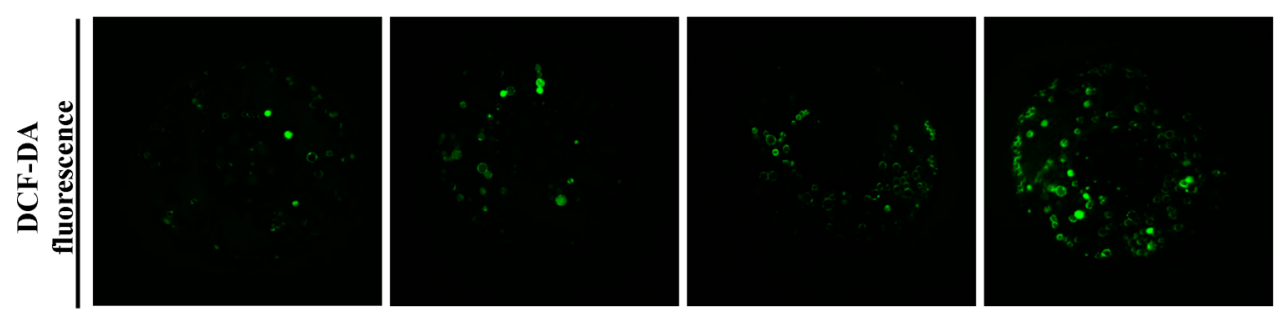

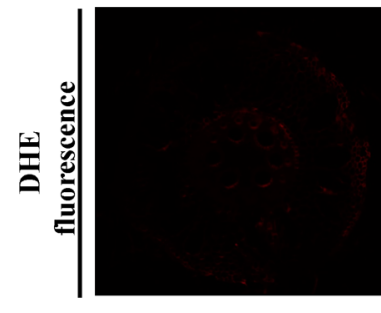

Control

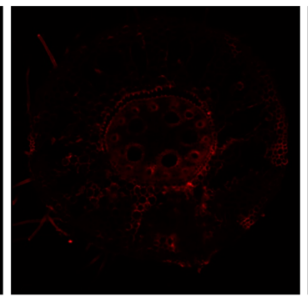

BDE-47

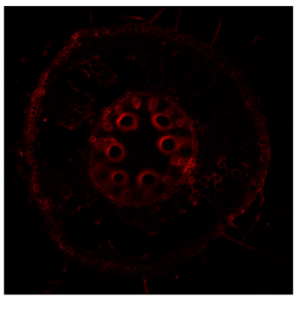

6-MeO-BDE-47

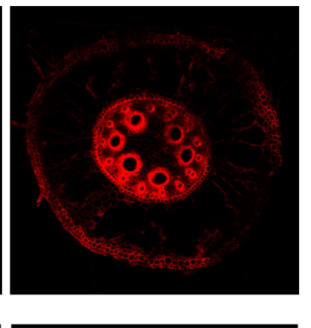

6-OH-BDE-47

B
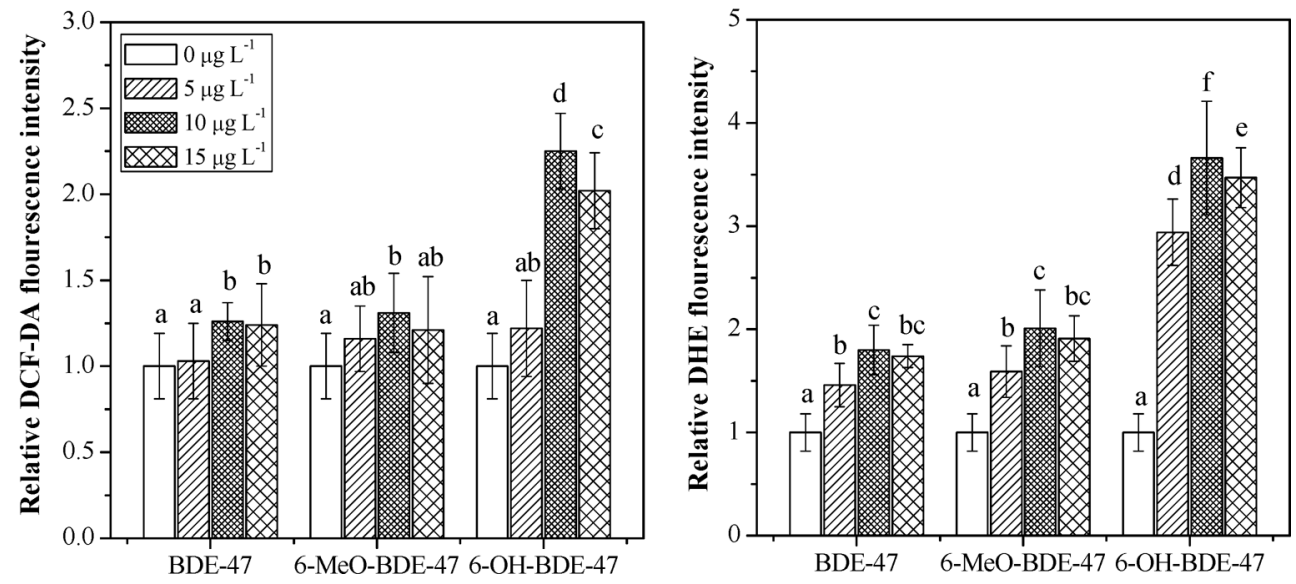

Figure 2. (A) CLSM detection of $\mathrm{O}_{2}{ }^{--}$and $\mathrm{H}_{2} \mathrm{O}_{2}$ with DHE and DCF-DA in cross-section of maize roots exposed to BDE-47, 6-OH-BDE-47, and 6-MeO-BDE-47 at concentrations of $10 \mu \mathrm{g} \mathrm{L}{ }^{-1}$. Locations of $\mathrm{O}_{2}{ }^{--}$and $\mathrm{H}_{2} \mathrm{O}_{2}$ are represented by red and green fluorescence, respectively. (B) Relative fluorescence intensity of DHE-derived $\mathrm{O}_{2}{ }^{--}$and DCF-DA-derived $\mathrm{H}_{2} \mathrm{O}_{2}$ signals. Values are the averages of at least three independent replicates. Different letters above bars represent significant differences between treatments $(P<0.05$; Duncan's test).

(Figure 1A). MDA is the end product of lipid peroxidation and can serve as a sensitive diagnostic index of oxidative injury in plants. ${ }^{36}$ These observations provide evidence that BDE-47, 6$\mathrm{MeO}-\mathrm{BDE}-47$, and 6-OH-BDE-47 induced lipid peroxidation in maize, with 6-OH-BDE-47 having a greater effect on the plant cell membrane than did BDE-47 or 6-MeO-BDE-47.

Production of carbonyl groups is a common feature to characterize oxidative modification of proteins. ${ }^{37}$ Treatment with BDE-47, 6-MeO-BDE-47, and 6-OH-BDE-47 elevated carbonyl group content in the maize roots by $52.4-89.4 \%$, $46.1-97.9 \%$, and $69.6-161.8 \%$, respectively (Figure 1B). This elevation was associated with exposure concentration increase, irrespective of the exposure compound. Formation of carbonyl groups resulting from the direct oxidation of an amino acid side chain is a compelling marker of protein modification due to the overproduction of ROS. ${ }^{38}$ An increase in the content of protein bound carbonyls indicated significant protein oxidation injury induced by oxidative stress in maize resulting from exposure to BDE-47, 6-MeO-BDE-47, and 6-OH-BDE-47.

DNA double strand breaks are one of the most serious DNA lesions compromising genomic integrity. ${ }^{39}$ The $\gamma$-H2AX foci are considered solid markers of DNA double strand breaks in plants. ${ }^{40}$ In this study, the content of $\gamma$-H2AX was measured to evaluate DNA damage in the maize exposed to BDE-47, 6$\mathrm{MeO}-\mathrm{BDE}-47$, and 6-OH-BDE-47. The levels of $\gamma$-H2AX foci in the roots were elevated in a dose-dependent manner when the exposure concentration increased from 0 to $10 \mu \mathrm{g} \mathrm{L}^{-1}$ and then decreased at concentration of $15 \mu \mathrm{g} \mathrm{L}^{-1}$ (Figure 1C). The increase in the yield of $\gamma-\mathrm{H} 2 \mathrm{AX}$ foci indicated that exposure to BDE-47, 6-MeO-BDE-47, and 6-OH-BDE-47 caused DNA 

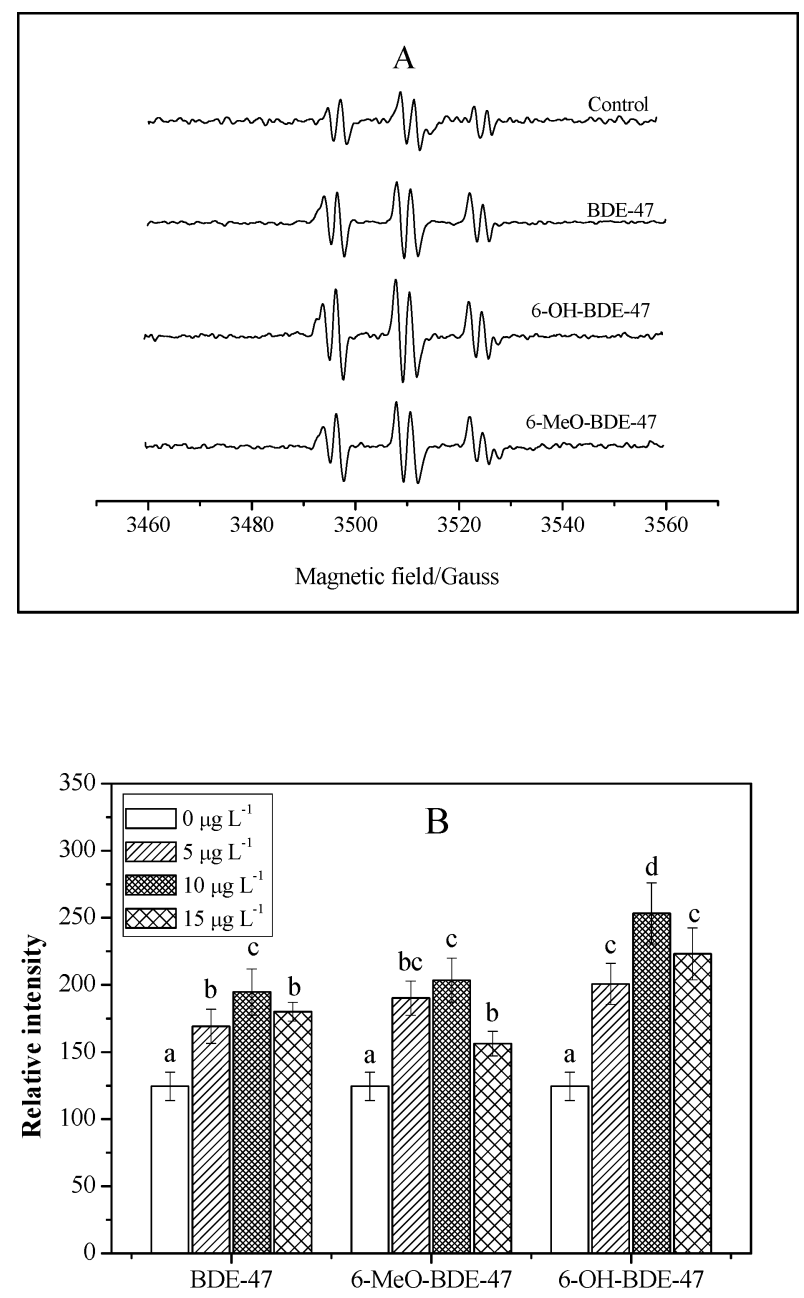

Figure 3. EPR detection of $\bullet \mathrm{OH}$ with $\mathrm{PBN}$ in maize roots exposed to BDE-47, 6-OH-BDE-47, and 6-MeO-BDE-47. (A) EPR spectra of the PBN-radical adduct in maize roots exposed to BDE-47, 6-OH-BDE47 , and 6-MeO-BDE-47 at concentrations of $10 \mu \mathrm{g} \mathrm{L}^{-1}$. (B) Radical relative intensity in roots exposed to different concentrations of BDE47, 6-OH-BDE-47, and 6-MeO-BDE-47. Different letters above bars represent significant differences between treatments $(P<0.05$; Duncan's test).

damage in maize. The decrease in $\gamma$-H2AX foci at the exposure concentration of $15 \mu \mathrm{g} \mathrm{L}^{-1}$ might be ascribed to self-repair of DNA damage. ${ }^{41}$ The most significant increase in the $\gamma$-H2AX foci was found for the 6-OH-BDE-47 treatment, consistent with previous research in which 6-OH-BDE-47 had a higher capability than 6-MeO-BDE-47 to induce DNA damage in HepG2 cells, as assessed by the alkaline comet assay. ${ }^{42}$

ROS Generation in Maize Roots. Previous research has reported that PBDEs, OH-PBDEs, and MeO-PBDEs can enhance the production of ROS in human and rat cells and cause oxidative stress. ${ }^{42,43}$ To assess whether the damage to lipids, proteins, and DNA induced by BDE-47, 6-MeO-BDE-47, and 6-OH-BDE-47 treatments was due to the overproduction of ROS, the level of ROS in maize roots was measured. The fluorescent assay is a powerful and convenient tool for monitoring ROS due to its superb sensitivity and temporalspatial resolution. ${ }^{44}$ Real-time generation of $\mathrm{O}_{2}{ }^{--}$and $\mathrm{H}_{2} \mathrm{O}_{2}$ was imaged by CLSM in maize root cross-sections using specific fluorescent probes, namely, DHE for $\mathrm{O}_{2}{ }^{--}$and DCFDA for $\mathrm{H}_{2} \mathrm{O}_{2}$ (Figure 2A). The fluorescence signal intensities
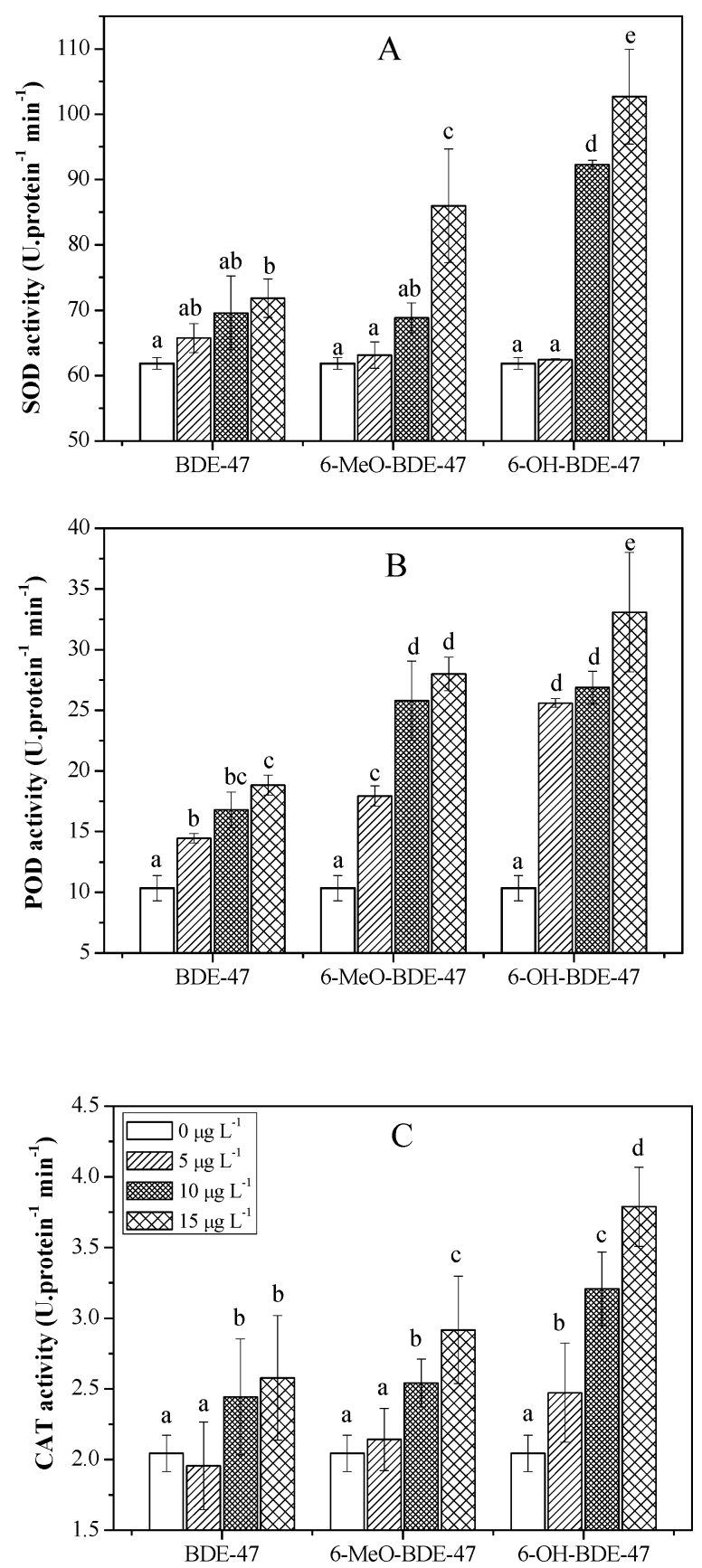

Figure 4. Activities of antioxidative enzymes in maize roots exposed to BDE-47, 6-OH-BDE-47, and 6-MeO-BDE-47: (A) SOD activity, (B) POD activity, and (C) CAT activity. Different letters above bars represent significant differences between treatments $(P<0.05$; Duncan's test).

for the BDE-47, 6-OH-BDE-47, and 6-MeO-BDE-47 treatments were significantly stronger than that of the control (Figure 2B), indicating that $\mathrm{BDE}-47,6-\mathrm{MeO}-\mathrm{BDE}-47$, and 6OH-BDE-47 induced the accumulation of $\mathrm{O}_{2}{ }^{\bullet-}$ and $\mathrm{H}_{2} \mathrm{O}_{2}$ and hence oxidative stress syndromes in maize. With the increase in exposure concentration from 5 to $10 \mu \mathrm{g} \mathrm{L}^{-1}$, the relative fluorescence signal intensities of DHE and DCF-DA increased; however, the intensities decreased when the exposure concentration was further increased from 10 to $15 \mu \mathrm{g} \mathrm{L}^{-1}$. The fluorescence intensity under the $10 \mu \mathrm{g} \mathrm{L}^{-1} 6-\mathrm{OH}-\mathrm{BDE}-47$ treatment was the greatest among all treatments. 
Both $\mathrm{O}_{2}{ }^{\bullet-}$ and $\mathrm{H}_{2} \mathrm{O}_{2}$ are only moderately reactive. ${ }^{45,46}$ They may be transformed through the Fenton reaction into the much more dangerous $\bullet \mathrm{OH}$ radicals, which are the most reactive species among all ROS and can immediately react with surrounding molecules after generation. ${ }^{47}$ Spin trapping-EPR was employed to determine $\bullet \mathrm{OH}$ generation in the maize roots. The relative intensity of $\bullet \mathrm{OH}$ was calculated by the signal intensity of the second couple of the triplet. Results showed that exposure to BDE-47, 6-MeO-BDE-47, and 6-OHBDE-47 resulted in a significant elevation in $\bullet \mathrm{OH}$ accumulation in the roots $(P<0.05$, Figure 3$)$. It is interesting to note that the increasing tendency for each compound was similar to the generation of $\mathrm{O}_{2}^{\bullet-}$ and $\mathrm{H}_{2} \mathrm{O}_{2}$ in maize roots. These analyses provide solid evidence that exposure to BDE-47, 6-MeO-BDE47 , and $6-\mathrm{OH}-\mathrm{BDE}-47$ led to the accumulation of ROS in the roots, which further induced oxidative stress in maize.

Antioxidation Enzyme Responses. Plants have antioxidant defense systems comprising POD, SOD, and CAT, which play important roles in scavenging ROS produced under oxidative stress. ${ }^{48}$ Increases in the activities of antioxidant enzymes are symptoms of oxidative stress induced by the enhanced production of ROS. Changes in POD, SOD, and $\mathrm{CAT}$ in maize roots resulted from the exposure of BDE-47, 6MeO-BDE-47, and 6-OH-BDE-47 (Figure 4). The activities of $\mathrm{POD}, \mathrm{SOD}$, and CAT were enhanced in a concentrationdependent manner after BDE-47, 6-OH-BDE-47, and 6-MeO$\mathrm{BDE}-47$ exposure and reached a maximum when the exposure concentration was $15 \mu \mathrm{g} \mathrm{L}^{-1}$, similar to the changes in ROS accumulation in the roots with increasing exposure concentration (Figures $2 \mathrm{~B}$ and $3 \mathrm{~B}$ ). For different compounds, the greatest increase in enzyme activity was observed in the 6-OHBDE-47 treatment. Taking the exposure concentration of $15 \mu \mathrm{g}$ $\mathrm{L}^{-1}$ as an example, the activities of POD, SOD, and CAT in the 6-OH-BDE-47 treatment were $42.9 \%, 75.6 \%$, and $47.0 \%$ higher than those of the BDE- 47 treatment, respectively, and $19.5 \%$, $18.2 \%$, and $29.9 \%$ higher than those of the 6-MeO-BDE-47 treatment, respectively. Activation of antioxidant enzymes is associated with plant detoxification. SOD constitutes the first line of defense against $\mathrm{O}_{2} \cdot-$ by rapidly converting $\mathrm{O}_{2}^{\bullet-}$ to $\mathrm{O}_{2}$ and $\mathrm{H}_{2} \mathrm{O}_{2}$ in the intrinsic antioxidant system of plants. ${ }^{49}$ CAT and POD catalyze the dismutation of $\mathrm{H}_{2} \mathrm{O}_{2}$ into nontoxic $\mathrm{O}_{2}$ and $\mathrm{H}_{2} \mathrm{O} .{ }^{50}$ Thus, the increase in the antioxidation enzyme activity indicated notable oxidative stress in maize caused by BDE-47, 6-MeO-BDE-47, and 6-OH-BDE-47.

BDE-47, 6-MeO-BDE-47, and 6-OH-BDE-47 induced lipid peroxidation, protein carbonylation, and DNA damage in maize roots. The toxicity was in the following order: 6-OH-BDE-47 > $6-\mathrm{MeO}-\mathrm{BDE}-47 \geq \mathrm{BDE}-47$, somewhat similar to the observations for other organisms such as Escherichia coli, fish, and rats. ${ }^{18,19,22}$ The addition of the $\mathrm{OH}$ and $\mathrm{MeO}$ groups to the backbone of BDE-47 significantly increased the toxicities of the 6-OH-BDE-47 and 6-MeO-BDE-47 compared to that of their precursor analogue BDE-47. The hydroxyl group in the backbone of BDE-47 is a good proton donor. It can form hydrogen bonds with water molecules to enhance the water solubility of 6-OH-BDE- $47^{51}$ and with biological molecules to stimulate and/or gain its binding and interaction with biological molecules such as DNA and protein, ${ }^{52,53}$ leading to the damage of protein and DNA in maize roots. The oxygen atom of the methoxy group on the backbone of BDE-47 is a proton acceptor, which can also form weak hydrogen bonds. ${ }^{54}$ The accumulation of $\mathrm{O}_{2}^{\bullet-}, \mathrm{H}_{2} \mathrm{O}_{2}$, and $\bullet \mathrm{OH}$ in maize roots, together with the increases in antioxidation enzyme activities, revealed that ROS overproduction played a key role in the toxic effects. To our knowledge, this is the first study to compare the phytotoxicity of a PBDE congener with its hydroxylated and methoxylated analogues. The results of this study provide direct evidence for ROS generation in maize due to PBDEs and hydroxylated/methoxylated PBDEs exposure, and suggest that overproduction of ROS is the key mechanism of BDE-47, 6$\mathrm{MeO}-\mathrm{BDE}-47$, and 6-OH-BDE-47 toxicity in maize.

\section{ASSOCIATED CONTENT}

\section{Supporting Information}

Detailed procedures for the analyses of MDA, free carbonyl groups, $\gamma$-H2AX, and antioxidation enzyme activities (including $\mathrm{SOD}, \mathrm{POD}$, and CAT). This material is available free of charge via the Internet at http://pubs.acs.org.

\section{AUTHOR INFORMATION}

\section{Corresponding Author}

*Tel: 010-62849683. Fax: 010-62923563. E-mail: szzhang@ rcees.ac.cn.

\section{Funding}

This work was funded by the National Natural Science Foundation of China (Projects 21321004 and 21177139) and the Chinese Academy of Sciences (Projects XDB14020202 and YSW2013B01).

\section{Notes}

The authors declare no competing financial interest.

\section{ABBREVIATIONS}

OH-PBDEs, hydroxylated PBDEs; MeO-PBDEs, methoxylated PBDEs; MDA, malondialdehyde; $\gamma$-H2AX foci, phosphorylated histones $\mathrm{H} 2 \mathrm{AX}$; ROS, reactive oxygen species; SOD, superoxide dismutase; POD, peroxidases; CAT, catalase; PBN, $\alpha$ phenyl-N-tert-butylnitrone; DHE, dihydroethidium; DCF-DA, $2^{\prime}, 7^{\prime}$-dichlorofluorescein diacetate; DNPH, 2,4-dinitrophenylhydrazine; DMSO, dimethyl sulfoxide; EPR, electro paramagnetic resonance; CLSM, confocal laser-scanning microscope; PBS, phosphate buffered solution

\section{REFERENCES}

(1) Brown, D. J., Van Overmeire, I., Goeyens, L., Denison, M. S., De Vito, M. J., and Clark, G. C. (2004) Analysis of Ah receptor pathway activation by brominated flame retardants. Chemosphere 57, 15091518.

(2) Hites, R. A. (2004) Polybrominated diphenyl ethers in the environment and in people: A meta-analysis of concentrations. Environ. Sci. Technol. 38, 945-956.

(3) Kelly, B. C., Ikonomou, M. G., Blair, J. D., and Gobas, F. A. P. C. (2008) Hydroxylated and methoxylated polybrominated diphenyl ethers in a Canadian Arctic marine food web. Environ. Sci. Technol. 42, 7069-7077.

(4) Wang, S., Zhang, S. Z., Huang, H. L., Lu, A. X., and Ping, H. (2012) Debrominated, hydroxylated and methoxylated metabolism in maize (Zea mays L.) exposed to lesser polybrominated diphenyl ethers (PBDEs). Chemosphere 89, 1295-1301.

(5) Qiu, X., Bigsby, R. M., and Hites, R. A. (2009) Hydroxylated metabolites of polybrominated diphenyl ethers in human blood samples from the United States. Environ. Health Perspect. 117, 93-98.

(6) Ueno, D., Darling, C., Alaee, M., Pacepavicius, G., Teixeira, C., Campbell, L., Letcher, R. J., Bergman, A., Marsh, G., and Muir, D. (2008) Hydroxylated polybrominated diphenyl ethers (OH-PBDEs) in the abiotic environment: Surface water and precipitation from Ontario, Canada. Environ. Sci. Technol. 42, 1657-1664. 
(7) Zhang, K., Wan, Y., Jones, P. D., Wiseman, S., Giesy, J. P., and $\mathrm{Hu}, \mathrm{J}$. Y. (2012) Occurrences and fates of hydroxylated polybrominated diphenyl ethers in marine sediments in relation to trophodynamics. Environ. Sci. Technol. 46, 2148-2155.

(8) Wang, S., Zhang, S. Z., Huang, H. L., Niu, Z. C., and Han, W. (2014) Characterization of polybrominated diphenyl ethers (PBDEs) and hydroxylated and methoxylated PBDEs in soils and plants from an e-waste area, China. Environ. Pollut. 184, 405-413.

(9) Zhou, J., Chen, J., Liang, C. H., Xie, Q., Wang, Y. N., Zhang, S., Qiao, X., and Li, X. (2011) Quantum chemical investigation on the mechanism and kinetics of PBDE photooxidation by $\bullet \mathrm{OH}$ : A case study for BDE-15. Environ. Sci. Technol. 45, 4839-4845.

(10) Kim, U. J., Yen, N. T., and Oh, J. E. (2014) Hydroxylated, methoxylated, and parent polybrominated diphenyl ethers (PBDEs) in the inland environment, Korea, and potential $\mathrm{OH}$ and $\mathrm{MeO}-\mathrm{BDE}$ source. Environ. Sci. Technol. 48, 7245-7253.

(11) Huang, H. L., Zhang, S. Z., Christie, P., Wang, S., and Xie, M. (2010) Behavior of decabromodiphenyl ether (BDE-209) in the soil plant system: uptake, translocation, and metabolism in plants and dissipation in soil. Environ. Sci. Technol. 44, 663-670.

(12) Sun, J. T., Liu, J. Y., Liu, Y. W., Yu, M., and Jiang, G. B. (2014) Reciprocal transformation between hydroxylated and methoxylated polybrominated diphenyl ethers in young whole pumpkin plants. Environ. Sci. Technol. Lett. 1, 236-241.

(13) Sun, J. T., Liu, J. Y., Liu, Y. W., and Jiang, G. B. (2013) Levels and distribution of methoxylated and hydroxylated polybrominated diphenyl ethers in plant and soil samples surrounding a seafood processing factory and a seafood market. Environ. Pollut. 176, 100105.

(14) Johansson, N., Viberg, H., Fredriksson, A., and Eriksson, P. (2008) Neonatal exposure to deca-brominated diphenyl ether (PBDE 209) causes dose-response changes in spontaneous behaviour and cholinergic susceptibility in adult mice. Neurotoxicology 29, 911-919.

(15) Siddiqi, M. A., Laessig, R. H., and Reed, K. D. (2003) Polybrominated diphenyl ethers (PBDEs): new pollutants-old diseases. Clin. Med. Res. 1, 281-290.

(16) Hamers, T., Kamstra, J. H., Sonneveld, E., Murk, A. J., Kester, M. H., Andersson, P. L., Legler, J., and Brouwer, A. (2006) In vitro profiling of the endocrine-disrupting potency of brominated flame retardants. Toxicol. Sci. 92, 157-173.

(17) Meerts, I., Letcher, R. J., Hoving, S., Marsh, G., Bergman, A., Lemmen, J. G., van der Burg, B., and Brouwer, A. (2001) In vitro estrogenicity of polybrominated diphenyl ethers, hydroxylated PDBEs, and polybrominated bisphenol A compounds. Environ. Health Perspect. 109, 399-407.

(18) Su, G. Y., Zhang, X. W., Liu, H. L., Giesy, J. P., Lam, M. H., Lam, P. K., Siddiqui, M. A., Musarrat, J., Al-Khedhairy, A., and Yu, H. X. (2012) Toxicogenomic mechanisms of 6-HO-BDE-47, 6-MeO-BDE47, and BDE-47 in E. coli. Environ. Sci. Technol. 46, 1185-1191.

(19) Su, G. Y., Xia, J., Liu, H. L., Lam, M. H. W., Yu, H. X., Giesy, J. P., and Zhang, X. W. (2012) Dioxin-like potency of HO- and MeOanalogues of PBDEs: the potential risk through consumption of fish from Eastern China. Environ. Sci. Technol. 46, 10781-10788.

(20) Ucán-Marin, F., Arukwe, A., Mortensen, A. S., Gabrielsen, G. W., and Letcher, R. J. (2010) Recombinant albumin and transthyretin transport proteins from two gull species and human: chlorinated and brominated contaminant binding and thyroid hormones. Environ. Sci. Technol. 44, 497-504.

(21) Wang, X. X., Yang, H. Y., Hu, X. X., Zhang, X. W., Zhang, Q. S., Jiang, H. L., Shi, W., and Yu, H. X. (2013) Effects of HO-/MeOPBDEs on androgen receptor: in vitro investigation and helix 12involved MD simulation. Environ. Sci. Technol. 47, 11802-11809.

(22) Lilienthal, H., Hack, A., Roth-Harer, A., Grande, S. W., and Talsness, C. E. (2006) Effects of developmental exposure to 2,2',4,4',5-pentabromodiphenyl ether (PBDE-99) on sex steroids, sexual development, and sexually dimorphic behavior in rats. Environ. Health Perspect. 114, 194-201.

(23) Zota, A. R., Park, J. S., Wang, Y., Petreas, M., Zoeller, R. T., and Woodruff, T. J. (2011) Polybrominated diphenyl ethers, hydroxylated polybrominated diphenyl ethers, and measures of thyroid function in second trimester pregnant women in California. Environ. Sci. Technol. 45, 7896-7905.

(24) Aravind, P., and Prasad, M. N. V. (2003) Zinc alleviates cadmium-induced oxidative stress in Ceratophyllum demersum L.: a free floating freshwater macrophyte. Plant Physiol. Biochem. 41, 391-397.

(25) Levine, R. L., Williams, J. A., Stadtman, E. R., and Shacter, E. (1994) Carbonyl assays for determination of oxidatively modified proteins. Methods Enzymol. 233, 346-357.

(26) Wu, T., Li, X. Y., Huang, H. L., and Zhang, S. Z. (2011) Enantioselective oxidative damage of chiral pesticide dichlorprop to maize. J. Agric. Food Chem. 59, 4315-4320.

(27) Bradford, M. M. (1976) A rapid and sensitive method for quantitation of microgram quantities of protein utilizing principle of protein dye-binding. Anal. Biochem. 72, 248-254.

(28) Aebi, H. (1984) Catalase in vitro. Methods Enzymol. 105, 121126.

(29) Beauchamp, C., and Fridovich, I. (1971) Superoxide dismutase: improved assays and an assay applicable to acrylamide gels. Anal. Biochem. 44, 276-287.

(30) Lagrimini, L. M. (1991) Wound-induced deposition of polyphenols in transgenic plants overexpressing peroxidase. Plant Physiol. 96, 577-583.

(31) Tanou, G., Ziogas, V., Belghazi, M., Christou, A., Filippou, P., Job, D., Fotopoulos, V., and Molassiotis, A. (2014) Polyamines reprogram oxidative and nitrosative status and the proteome of citrus plants exposed to salinity stress. Plant, Cell Environ. 37, 864-885.

(32) Wen, B., Liu, Y., Wang, P., Wu, T., Zhang, S. Z., Shan, X. Q., and $\mathrm{Lu}$, J. F. (2012) Toxic effects of chlortetracycline on maize growth, reactive oxygen species generation and the antioxidant response. $J$. Environ. Sci. (Beijing, China) 24, 1099-1105.

(33) Zeid, M. (2001) Responses of Phaseolus vulgaris to chromium and cobalt treatments. Biol. Plant. 44, 111-115.

(34) An, J., Zhou, Q. X., Sun, F. H., and Zhang, L. (2009) Ecotoxicological effects of paracetamol on seed germination and seedling development of wheat (Triticum aestivum L.). J. Hazard. Mater. 169, 751-757.

(35) Werner, T., Nehnevajova, E., Köllmer, I., Novák, O., Strnad, M., Krämer, U., and Schmülling, T. (2010) Root-specific reduction of cytokinin causes enhanced root growth, drought tolerance, and leaf mineral enrichment in Arabidopsis and tobacco. Plant Cell 22, 39053920.

(36) Yaacoub, R., Saliba, R., Nsouli, B., Khalaf, G., and BirlouezAragon, I. (2008) Formation of lipid oxidation and isomerization products during processing of nuts and sesame seeds. J. Agric. Food Chem. 56, 7082-7090.

(37) Møller, I. M., and Kristensen, B. K. (2004) Protein oxidation in plant mitochondria as a stress indicator. Photochem. Photobiol. Sci. 3, $730-735$.

(38) Romero-Puertas, M. C., Gómez, J. M., Del Río, L. A., and Sandalio, L. M. (2002) Cadmium causes the oxidative modification of proteins in pea plants. Plant, Cell Environ. 25, 677-686.

(39) Jackson, S. P. (2002) Sensing and repairing DNA double-strand breaks. Carcinogenesis 23, 687-696.

(40) Lang, J., Smetana, O., Sanchez-Calderon, L., Lincker, F., Genestier, J., Schmit, A. C., Houlné, G., and Chabouté, M. E. (2012) Plant $\gamma \mathrm{H} 2 \mathrm{AX}$ foci are required for proper DNA DSB repair responses and colocalize with E2F factors. New Phytol. 194, 353-363.

(41) Macphail, S. H., Banáth, J. P., Yu, T. Y., Chu, E. H. M., Lambur, H., and Olive, P. L. (2003) Expression of phosphorylated histone $\mathrm{H} 2 \mathrm{AX}$ in cultured cell lines following exposure to X-rays. Int. J. Radiat. Biol. 79, 351-358.

(42) An, J., Li, S. H., Zhong, Y. F., Wang, Y. P., Zhen, K. W., Zhang, X. Y., Wang, Y. J., Wu, M. H., Yu, Z. Q., Sheng, G. Y., Fu, J. M., and Huang, Y. C. (2011) The cytotoxic effects of synthetic 6-hydroxylated and 6-methoxylated polybrominated diphenyl ether 47 (BDE47). Environ. Toxicol. 26, 591-599. 
(43) He, P., He, W., and Wang, A. (2008) PBDE-47-inducted oxidative stress, DNA damage and apoptosis in primary cultured rat hippocampal neurons. Neurotoxicology 29, 124-129.

(44) Hirosawa, S., Arai, S., and Takeoka, S. (2012) A TEMPOconjugated fluorescent probe for monitoring mitochondrial redox reactions. Chem. Commun. 48, 4845-4847.

(45) Gozzo, F. (2003) Systemic acquired resistance in crop protection: from nature to a chemical approach. J. Agric. Food Chem. 51, 4487-4503.

(46) Mittler, R., and Zilinskas, B. A. (1991) Purification and characterization of pea cytosolic ascorbate peroxidase. Plant Physiol. 97, 962-968.

(47) Halliwell, B., and Gutteridge, J. M. C. (2007) Free Radicals in Biology and Medicine, 4th ed.; Oxford University Press, Oxford, U. K.

(48) Alscher, R. G., and Hess, J. L. (1993) Antioxidants in Higher Plants, CRC Press, Boca Raton, FL.

(49) Alscher, R. G., Erturk, N., and Heath, L. S. (2002) Role of superoxide dismutases (SODs) in controlling oxidative stress in plants. J. Exp. Bot. 53, 1331-1341.

(50) Tripathi, B. N., Mehta, S. K., Amar, A., and Gaur, J. P. (2006) Oxidative stress in Scenedesmus sp. during short- and long-term exposure to $\mathrm{Cu}^{2+}$ and $\mathrm{Zn}^{2+}$. Chemosphere 62, 538-544.

(51) Su, G., Yu, H., Lam, M. H., Giesy, J. P., and Zhang, X. (2014) Mechanisms of toxicity of hydroxylated polybrominated diphenyl ethers (HO-PBDEs) determined by toxicogenomic analysis with a live cell array coupled with mutagenesis in Escherichia coli. Environ. Sci. Technol. 48, 5929-5937.

(52) Grimm, F. A., Lehmler, H. J., He, X. R., Robertson, L. W., and Duffel, M. W. (2013) Sulfated metabolites of polychlorinated biphenyls are high-affinity ligands for the thyroid hormone transport protein transthyretin. Environ. Health Perspect. 121, 657-662.

(53) Li, F., Li, X. H., Liu, X. L., Zhang, L. B., You, L. P., Zhao, J. M., and $\mathrm{Wu}, \mathrm{H}$. F. (2011) Noncovalent interactions between hydroxylated polycyclic aromatic hydrocarbon and DNA: Molecular docking and QSAR study. Environ. Toxicol. Pharmacol. 32, 373-338.

(54) Palusiak, M., and Grabowski, S. J. (2002) Methoxy group as an acceptor of proton in hydrogen bonds. J. Mol. Struct. 642, 97-104. 